\title{
PROJECTING THE NEED FOR AND COST OF LONG-TERM CARE FOR OLDER PERSONS
}

Wendy Holmes

NO. 74

February 2021
ADB SUSTAINABLE DEVELOPMENT WORKING PAPER SERIES 



\section{ADB Sustainable Development Working Paper Series}

\section{Projecting the Need for and Cost of Long-Term Care for Older Persons}

Wendy Holmes

No. 74 | February 2021
Wendy Holmes, a consultant for the Asian

Development Bank, is an international public health physician with interests in the health of older people and population aging. She holds an honorary senior lecturer position in the School of Population and Global Health, University of Melbourne. 
(C) 2021 Asian Development Bank

6 ADB Avenue, Mandaluyong City, 1550 Metro Manila, Philippines

Tel +632 8632 4444; Fax +63286362444

www.adb.org

Some rights reserved. Published in 2021.

Publication Stock No. WPS210072-2

DOI: http://dx.doi.org/10.22617/WPS210072-2

The views expressed in this publication are those of the authors and do not necessarily reflect the views and policies of the Asian Development Bank (ADB) or its Board of Governors or the governments they represent.

ADB does not guarantee the accuracy of the data included in this publication and accepts no responsibility for any consequence of their use. The mention of specific companies or products of manufacturers does not imply that they are endorsed or recommended by ADB in preference to others of a similar nature that are not mentioned.

By making any designation of or reference to a particular territory or geographic area, or by using the term "country" in this document, $A D B$ does not intend to make any judgments as to the legal or other status of any territory or area.

This work is available under the Creative Commons Attribution 3.0 IGO license (CC BY 3.0 IGO)

https://creativecommons.org/licenses/by/3.0/igo/. By using the content of this publication, you agree to be bound by the terms of this license. For attribution, translations, adaptations, and permissions, please read the provisions and terms of use at https://www.adb.org/terms-use\#openaccess.

This CC license does not apply to non-ADB copyright materials in this publication. If the material is attributed to another source, please contact the copyright owner or publisher of that source for permission to reproduce it. ADB cannot be held liable for any claims that arise as a result of your use of the material.

Please contact pubsmarketing@adb.org if you have questions or comments with respect to content, or if you wish to obtain copyright permission for your intended use that does not fall within these terms, or for permission to use the ADB logo.

The ADB Sustainable Development Working Paper Series presents data, information, and/or findings from ongoing research and studies to encourage exchange of ideas and elicit comment and feedback about development issues in Asia and the Pacific. Since papers in this series are intended for quick and easy dissemination, the content may or may not be fully edited and may later be modified for final publication.

Corrigenda to ADB publications may be found at http://www.adb.org/publications/corrigenda.

Notes:

In this publication, “\$” refers to United States dollars.

ADB recognizes "China" as the People’s Republic of China and "Hong Kong" as Hong Kong, China. 


\section{CONTENTS}

TABLE, FIGURES, AND BOX iv

ACKNOWLEDGMENTS V v v v

ABBREVIATIONS vi

$\begin{array}{ll}\text { I. INTRODUCTION } & \mathbf{1}\end{array}$

II. UNDERSTANDING MODELING TO PROJECT FUTURE LONG-TERM CARE NEED, 2 DEMAND, AND COST
A. Definition 2
B. Need and Demand $\quad 2$
C. Measuring Need $\quad 4$
D. Measuring Demand $\quad 6$
E. Types of Modeling Methods $\quad 7$
F. Platforms for Decision-Support and Population-Aging Data 8

III. SYNTHESIS OF FINDINGS FROM REVIEW OF MODELING STUDIES 8

A. Number and Geographic Settings of Modeling Studies for Long-Term Care Needs 8

B. Characteristics of the Modeling Studies for Long-Term Care Needs 9

C. Consistency and Comparability of Findings 11

D. Key Projections from Modeling Studies for Long-Term Care Needs 13

$\begin{array}{lr}\text { IV. CONCLUSIONS } & 14\end{array}$

$\begin{array}{ll}\text { V. RECOMMENDATIONS } & 15\end{array}$

$\begin{array}{ll}\text { APPENDIXES } & 17\end{array}$

1 The Washington Group Short Set of Questions on Disability 17

2 Key Platforms for Decision-Support and Population-Aging Data 18 


\section{TABLE, FIGURES, AND BOX}

\section{TABLE}

Differences between the People's Republic of China Modeling Studies

\section{FIGURES}

1 Influences on the Need and Demand for Long-Term Care Services for Older People

2 Pathways of Disability Transitions in the Markov Model

BOX

What Is Long-Term Care? 


\section{ACKNOWLEDGMENTS}

This paper was prepared as part of the implementation of the Asian Development Bank (ADB) regional technical assistance, TA 9111: Strengthening Developing Member Countries' Capacity in Elderly Care, financed by the Japan Fund for Poverty Reduction and the Republic of Korea e-Asia and Knowledge Partnership Fund.

The author is grateful for useful insights and comments received from the following experts (in alphabetical order):

- Peter Chan, research fellow, Sau Po Centre of Ageing; lecturer, University of Hong Kong; deputy director, Institute of Ageing; professor, Beijing Normal University

- Adelina Comas-Herrera, assistant professorial research fellow, Personal Social Services Research Unit, London School of Economics

- Thanh Long Giang, director, Institute of Public Policy and Management, National Economics University, Hanoi; senior researcher, Institute of Social and Medical Studies, Hanoi; adjunct senior researcher, Menzies Institute of Medical Research, University of Tasmania, Australia; affiliate research fellow, IPAG Business School, Paris

- Paul Kowal, scientist, WHO Multi-Country Studies Unit; senior research fellow, University of Newcastle Research Centre on Gender, Health and Ageing

- Barbara McPake, director Nossal Institute, School of Population and Global Health, University of Melbourne

- Susie Perera, deputy director general (Health Services), Sri Lanka Ministry of Health

The paper also benefitted from further review and comments by (in alphabetical order):

- Caitlin Littleton, regional technical adviser, Health and Care, HelpAge International

- Wendy Walker, chief of the Social Development Thematic Group, Sustainable Development and Climate Change Department, Asian Development Bank

- Camilla Williamson, consultant-Aging and Older People

- Meredith Wyse, senior social development specialist-Aging and Care, Sustainable Development and Climate Change Department, Asian Development Bank 


\section{ABBREVIATIONS}

ADL activity of daily living

LMIC low-or middle-income country

LTC long-term care

IADL instrumental activity of daily living

OECD Organisation for Economic Co-operation and Development

PRC People's Republic of China 


\section{INTRODUCTION}

1. As a result of increasing life expectancy and decreasing fertility rates, the number of older people is growing in absolute terms and as a proportion of the population in Asia and the Pacific region. The region's population aged 60 years and above is expected to reach 1.26 billion in 2050 and increase from $11 \%$ in 2012 to $24 \%$ of the total population.

2. Population aging has major economic and social implications and raises concerns about who will provide long-term care (LTC) for those older people in need of care. In the region, as in the rest of the world, older people who need assistance are often cared for by family members, usually wives, daughters, and daughters-in-law. Cultural beliefs emphasize filial obligation toward parents in their old age, as well as the need to look after family members who lack adult children to care for them.

3. However, as current populations age, traditional family support systems are being eroded by expanding female labor market participation, smaller family size, and trends in migration. Even when family is available to provide care, people with complex care needs are likely to require additional support. These demographic and socioeconomic trends mean that a large gap is emerging between the need and demand for aged care and its supply. In response, countries and areas in the region are increasingly considering the development of comprehensive LTC systems.

4. Debates about the development of LTC systems raise several questions, including the number of older people who are likely to require LTC services in the coming decades, the cost of these services, and if public funds will prove adequate. ${ }^{1}$ To help answer these queries, modeling should be undertaken to provide projections of future need and demand for LTC and associated future LTC costs.

5. This paper aims to enhance the understanding - of policy makers and those planning modeling studies - of using statistical models to project the need, demand, and cost of LTC services in the region. Based on a review completed for the Asian Development Bank (ADB) by Wendy Holmes, ${ }^{2}$ this paper outlines modeling and its importance; describes LTC need, demand, and measurement; and describes key issues when designing and using models. A review of recent modeling studies is also summarized, drawing out lessons relevant to low- and middle- income countries (LMICs).

1 A. Comas-Herrera, R. Wittenberg, and L. Pickard. 2003. Making Projections of Long-Term Care: Examples and Methodological Issues. PSSRU Discussion Paper. London and Kent: London School of Economics and Political Science and University of Kent.

2 ADB. 2020. Projecting the Need for and Cost of Long-Term Care for Older Persons-A Modelling Review. Consultant's report. Manila (TA 9111). 


\section{What Is Long-Term Care?}

The World Report on Ageing and Health 2015 of the World Health Organization defines longterm care (LTC) as "the activities undertaken by others to ensure that people with or at risk of a significant ongoing loss of intrinsic capacity can maintain a level of functional ability consistent with their basic rights, fundamental freedoms, and human dignity." Capacity may be lost gradually or suddenly, some capacity may be recovered, and it is often possible to slow deterioration of capacity. Long-term activities can include psychosocial support, measures to help with activities of daily living and instrumental activities of daily living, and clinical care. They can be delivered in a range of settings, including homes, in the community at venues such as day-care centers and community centers, and in residential settings such as nursing homes. LTC is delivered by a range of people, including family members; health and care workers; social workers; and those from public, private, and voluntary organizations.

An LTC system consists of all of the organizations, institutions, resources, and people involved in carrying out LTC activities. It should ensure the delivery of integrated, appropriate, affordable, and accessible services. Ministries of health and of social services usually have responsibility for LTC services, although other ministries also have roles to play.

Source: WHO. 2015. World Report on Ageing and Health 2015. Geneva.

\section{UNDERSTANDING MODELING TO PROJECT FUTURE LONG-TERM CARE NEED, DEMAND, AND COST}

\section{A. Definition}

6. A model aims to imitate or to represent-as closely as possible-what happens in real life, using available data to make predictions about the future. Regarding LTC, modeling can be used to project care need, demand, and cost, based on a range of historical or current data and trends.

7. At the national or international level, modeling can inform development of LTC policy, investigate future affordability, and explore the implications of changes in patterns of care or funding mechanisms (footnote 1). At the local level, modeling can provide accurate short-term predictions that enable detailed planning of service provision and local budgets, based on local data and social trends.

\section{B. Need and Demand}

8. There is no international consensus on the definitions of care need and demand that are used by health economists and public health policy makers. ${ }^{3}$ In this paper, need is defined as the quantity of LTC services that a review of evidence suggests should be available over a relevant time period to ensure that older "people with or at risk of a significant ongoing loss of intrinsic capacity can maintain a

3 J. Jeffers, M. Bognanno, and J. Bartlett. 1971. On the Demand versus Need for Medical Services and the Concept of "Shortage." American Journal of Public Health. 61 (1). pp. 46-63. 
level of functional ability consistent with their basic rights, fundamental freedoms, and human dignity." Demand is an economic concept denoting a person's desire, ability, and willingness to use or to pay for a product or service. ${ }^{5}$

9. Several factors influence the need and demand for LTC (Figure 1). These are often difficult to measure and also often change over time. Each influencing factor is, in turn, affected by other factors, and sometimes these interact.

\section{Figure 1: Influences on the Need and Demand for Long-Term Care Services for Older People}

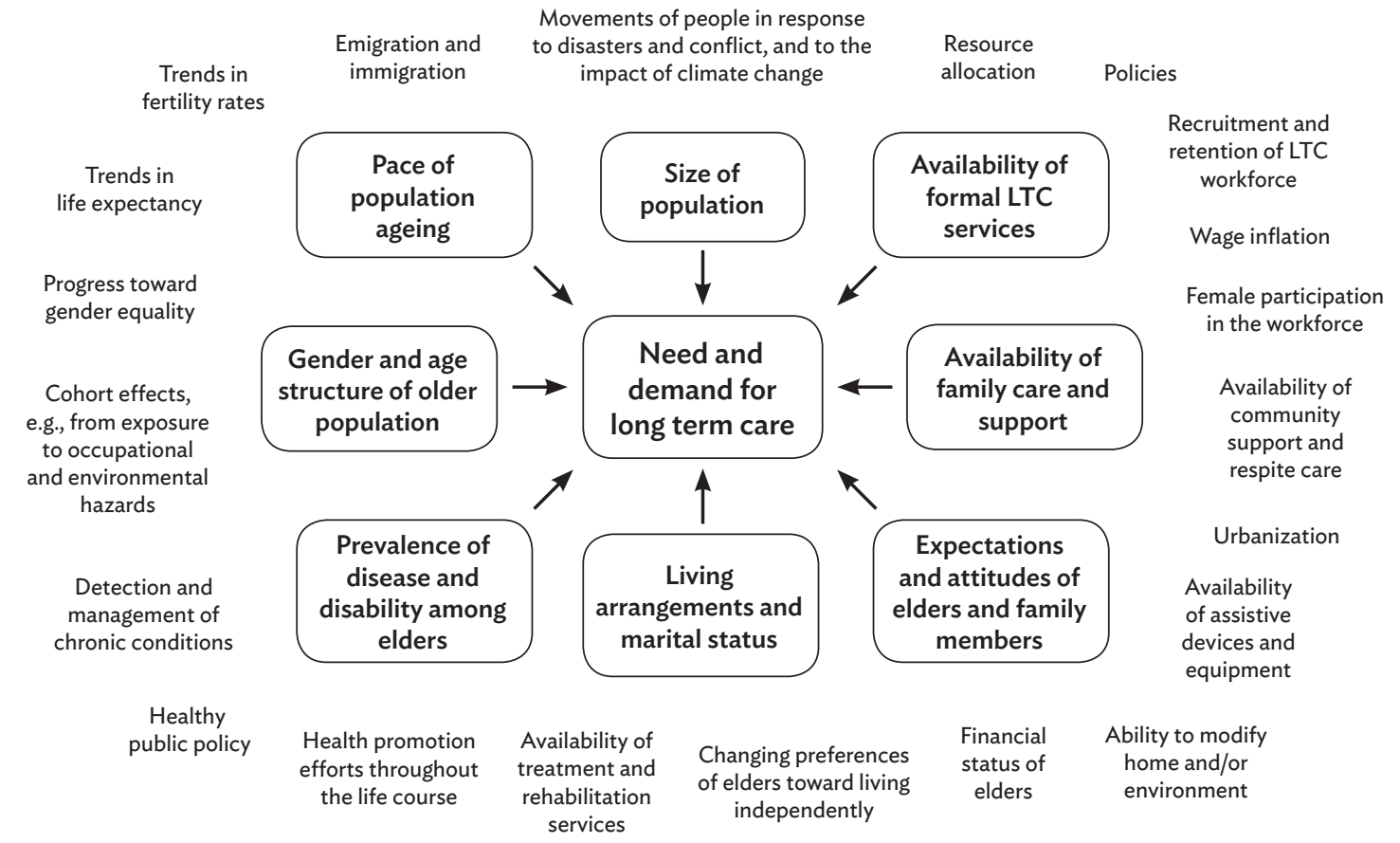

Source: Author.

10. While past trends can be considered and may persist, it is important to recognize that these can also change. For example, rates of disability in future older populations may be influenced by changes in nutrition and education; changes in levels of obesity, exercise, and consumption of alcohol and tobacco; as well as changes in health policies and services.

11. Ultimately, data availability determines the inclusion of potential drivers of need and demand for care in a model. Changes in the proportion of a population experiencing ill health can be projected where longitudinal data are available. ${ }^{6}$ Yet forecasts cannot anticipate all future drivers of health change,

4 WHO. 2015. World Report on Ageing and Health. Geneva.

5 M. Wren, et al. 2012. Towards the Development of a Predictive Model of Long-Term Care Demand for Northern Ireland and the Republic of Ireland. Dublin and Belfast: Trinity University and Queen's University Belfast. https://www.tcd.ie/medicine/ health_policy_management/assets/pdf/CARDIreport.pdf.

6 M. Lagergren, N. Kurube, and Y. Saito. 2018. Future Costs of Long-Term Care in Japan and Sweden. International Journal of Health Services. 48 (1). pp. 128-147. 
meaning there is inevitable uncertainty in the estimates that models generate. It is crucial, therefore, when presenting the findings of a model, to describe the methods used and their limitations, assumptions made, parameters or influencing factors included, as well as details of different scenarios when specific parameters vary.

12. In general, researchers try to strike a balance between a simple model, which takes too few of these influencing factors into account, and a complicated model with too much information, especially when several different scenarios are tested. As one study stated:

Such simulations are useful for the academic and policy analysis to answer the "what if" questions about effects of changes in demographics and disability status transition rates on the future general trends and patterns of elderly disability, home-based care needs and costs for disabled elders ... but they cannot be considered to be accurate forecasts.?

\section{Measuring Need}

13. The primary determinants of LTC need are the numbers of older people in a population by age and gender, and their level of disability and dependence.

14. Researchers use a variety of ways to measure disability and dependence. The most common measure for care need is a person's ability to perform activities of daily living (ADLs) or instrumental activities of daily living (IADLs). ADLs include activities such as moving from a bed to a chair, washing, grooming, and going to the toilet. Tools to measure ADLs often include a measure related to mobility, usually the ability to walk. ${ }^{8}$ Some also include questions about cognitive impairment and the ability to communicate with others. ${ }^{9}$ IADLs include more complex activities that a person needs to perform to be self-reliant at home and in the community, such as shopping, preparing meals, housework, and managing money, although these vary according to setting.

15. There are two comprehensive assessment scales for ADLs, the Katz Index of Independence in Activities of Daily Living and Barthel Index for Activities of Daily Living. ${ }^{10}$ The Katz index measures if a person is dependent or independent in six activities, which the older person is asked to demonstrate: bathing, dressing, toileting, transfers, continence, and feeding. His/her level of dependence is categorized by the amount of assistance needed to complete the task.

16. The Barthel index has 10 domains, which encompass those asked on the Katz index plus grooming, walking, the ability to use stairs, and use of a wheelchair. Again, dependence is categorized by the amount of assistance needed to complete the task. The score is expressed on a scale of 0-100, with 0 representing total dependency. Thailand national community-based care program eligibility necessitates a Barthel index score of 13 or lower, which indicates total dependency.

17. Some classify disability as needing help with any one ADL, but others categorize difficulties with ADLs and IADLs into different levels of dependency, depending on how many activities individuals need

7 Y. Zeng, H. Chen, Z. Wang, and K. Land. 2015. Implications of Changes in Households and Living Arrangements for Future Home-Based Care Needs and Costs for Disabled Elders in China. Journal of Aging and Health. 27 (3). pp. 519-550.

8 M. Lawton. 1971. The Functional Assessment of Elderly People. Journal of the American Geriatrics Society. 19 (6). pp. $456-481$.

9 B. Nepal, et al. 2011. Projecting the Need for Formal and Informal Aged Care in Australia: A Dynamic Micro-Simulation Approach. National Centre for Social and Economic Modeling Working Paper Series. No. 11/07. Canberra: University of Canberra; and E. Leung. 2003. Projecting the Needs and Costs of Long-Term Care in Australia. Centre for Actuarial Studies Research Papers. No. 110. Melbourne: The University of Melbourne. https://fbe.unimelb.edu.au/__data/assets/pdf_ file/0005/2592050/110.pdf.

${ }^{10}$ F. Mahoney, and D. Barthel. 1965. Functional Evaluation: The Barthel Index. Maryland State Medical Journal. 14. pp. 61-65. 
assistance with, ranging from "no or slight dependency" to "very severe dependency." In a Singapore model, for example, researchers chose a cut-off between two and three ADL limitations, because a government-sponsored LTC insurance scheme defines severe disability as being unable to perform at least three of six ADLs. Sometimes, researchers include "self-reported health;" however, one study found that this predicted need for LTC less well than difficulties with ADLs."

18. Many national census questionnaires also include questions about disability. The United Nations Statistical Commission recommends the use of a short set of disability questions developed by the Washington Group on Disability Statistics (Appendix 1). As with the Katz and Barthel indexes, these questions focus on limitations in basic activity functioning. However, as census formats require a limited number of questions for each statistic to be produced, the Washington Group questions focus on six domains of functioning (i.e., seeing, hearing, walking, remembering or concentrating, self-care such as washing all over or dressing, and communicating in the customary language), asking the individual to indicate for each if he/she has "no difficulty," "some difficulty," "a lot of difficulty," or if he/she "cannot do [the function] at all."

19. The purpose of these questions is not to identify all persons with disabilities but rather to gather information that represents the majority of people with limitations in basic activity functioning in any one country or area, represents the most common limitations in basic activity functioning within any country or area, and captures people with similar problems across countries or areas. ${ }^{12}$ The use of the Washington Group questions represents the best practice in providing comparable data cross-nationally for populations living in a wide variety of cultures with varying economic resources. To date, over 60 countries and areas have used these questions in censuses or surveys to collect information on disability as part of the 2020 round of censuses.

20. Regardless of source or method, it is important to note the challenges of using disability as a proxy for LTC need. As illustrated above, there can be significant differences in definitions, data collection methods, and question wording, leading to considerable variation in estimates of disability prevalence between data sources. ${ }^{13}$ Methodological difficulties in studying disability and health conditions among older people can also result in selection, information, and respondent bias, affecting the validity of study results. This should be considered when designing or selecting data for models.

21. It is also important to recognize that older people's need for assistance and care can change, sometimes suddenly. For example, a fit and independent older person may experience a stroke, which results in immediate severe disability and requires a high level of care. With rehabilitation, however, he/ she may recover and spend time at a lower level of need for care. Eventually, he/she may even become fully independent again-before becoming increasingly frail and needing some assistance with IADLs. The range of possible transitions is shown in Figure 2.

22. Longitudinal surveys with regular waves of data collection that include questions on the ability to perform ADLs can provide data on the frequency of transitions between different states of the need for care. Different pathways of these disability transitions can be considered through a statistical technique called Markov modeling, which uses a probability for each possible transition. It must be noted, however,

11 M. Lagergren, N. Kurube, and Y. Saito. 2018. Future Costs of Long-Term Care in Japan and Sweden. International Journal of Health Services. 48 (1). pp. 128-147.

12 Washington Group on Disability Statistics. Statement of Rationale for the Washington Group General Measure on Disability. http://www.washingtongroup-disability.com/wp-content/uploads/2016/01/Rationale_WG_Short-1.pdf.

13 S. Mitra, and U. Sambamoorthi. 2006. Disability Estimates in India: What the Census and NSS Tell Us. Economic and Political Weekly. 41 (38). pp. 4022-4026; UNESCAP. 2016. Long-Term Care of Older Persons in Sri Lanka. Bangkok. http://www. unescap.org/resources/long-term-care-older-persons-sri-lanka; and M. Parmar, and N. Saikia. 2018. Chronic Morbidity and Reported Disability among Older Persons from the India Human Development Survey. BMC Geriatrics. 18 (1). 
Figure 2: Pathways of Disability Transitions in the Markov Model

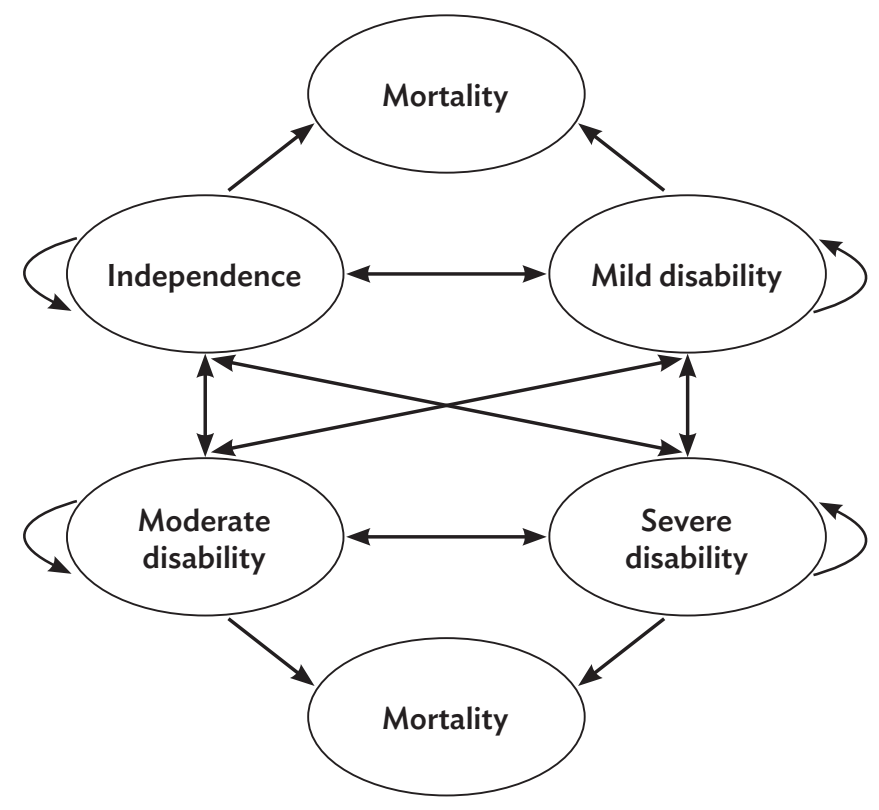

Source: B. Hu. 2019. Projecting Future Demand for Informal Care among Older People in China: The Road towards a Sustainable Long-Term Care System. Health Economics, Policy and Law. 14 (1). pp. 61-81.

that measurements of need for care do not generally include assessment of some conditions that could benefit from social interventions, such as loneliness, grief, mental health problems, addiction, and poverty.

\section{Measuring Demand}

23. Demand for LTC is influenced by need and other factors, including marital status, household composition, female labor force participation, socioeconomic status, geography, and the supply of care, whether informal or formal and in all settings. ${ }^{14}$

24. Most statistical models used in high-income countries take demand into account in addition to need, and trends in the current use of LTC services can be extrapolated. However, in many LMICs in the region, formal LTC services are not yet widely available, so this approach is not possible. Indeed, few modeling studies from LMICs have considered demand or current receipt of formal LTC services. In addition, the range of factors that influence demand, particularly those related to socioeconomics and the supply of formal and informal care, mean that caution should be taken in using current service use as a proxy for demand.

${ }^{14}$ M. Wren, et al. 2012. Towards the Development of a Predictive Model of Long-Term Care Demand for Northern Ireland and the Republic of Ireland. Dublin and Belfast: Trinity University and Queen's University Belfast. https://www.tcd.ie/medicine/ health_policy_management/assets/pdf/CARDIreport.pdf. 


\section{E. Types of Modeling Methods}

25. There are several methods to project LTC need, demand, and expenditure. The best method depends on the purpose of the projections and available data. Broadly, there are two main approaches to making projections, macrosimulation (or cell-based) and microsimulation models. With macrosimulation, the unit of analysis is individuals grouped into "cells" by characteristics such as age and gender. The simplest form consists of applying the current average costs of care for people of each age group (and sometimes gender) to the future numbers of people in that group. With microsimulation, the unit of analysis is individual people, families, or households. This modeling is based on large-scale representative samples used to simulate changes in individuals' disability status, care utilization, and expenditure. ${ }^{15}$

26. Most LTC models are macrosimulations, not only because they are a simpler method of making projections, but also because in many countries and territories the data required for microsimulation models are not available. While it is possible to develop sophisticated systems of scenarios that consider multiple variables, macrosimulation models tend to be straightforward and are built using a spreadsheet. ${ }^{16}$ Another benefit of macrosimulation models is that they can be more readily adapted to available data sources than microsimulation models.

27. Depending on their complexity, the data requirements for such models include

(i) population projections by age and gender;

(ii) disability prevalence or trends by age and gender;

(iii) disability projections by age and gender;

(iv) utilization patterns of formal care by age, gender, and disability status;

(v) utilization of informal care by age, gender, and disability status;

(vi) household composition projections by age and gender;

(vii) receipt of informal care by household type; and

(viii) housing tenure, socioeconomic status, income, and assets. ${ }^{17}$

28. The model developed by Care Policy and Evaluation Centre in the United Kingdom is an example. ${ }^{18}$ It projects the numbers of older people divided by subgroups or cells, which are defined by age, dependency, gender, household type, housing tenure (a proxy for socioeconomic group), and receipt of informal care. LTC demand is then projected based on current patterns of use, with the probability of receiving health and social care services attached to each cell.

29. Most models make use of Sullivan's method to calculate health expectancy, also known as disability-free life expectancy (i.e., the number of remaining years, at a particular age, that an individual can expect to live in a healthy state). This is calculated by subtracting the probable duration of disability and inability to perform major activities from life expectancy, based on data from population surveys and

15 A. Comas-Herrera, R. Wittenberg, and L. Pickard. 2003. Making Projections of Long-Term Care: Examples and Methodological Issues. PSSRU Discussion Paper. London and Kent: London School of Economics and Political Science and University of Kent.

16 Footnote 15.

17 M. Wren, et al. 2012. Towards the Development of a Predictive Model of Long-Term Care Demand for Northern Ireland and the Republic of Ireland. Dublin and Belfast: Trinity University and Queen's University Belfast. https://www.tcd.ie/medicine/ health_policy_management/assets/pdf/CARDIreport.pdf.

18 A. Comas-Herrera, R. Wittenberg, and L. Pickard. 2003. Making Projections of Long-Term Care: Examples and Methodological Issues. PSSRU Discussion Paper. London and Kent: London School of Economics and Political Science and University of Kent. 
period life tables. Sullivan's method reflects the current health of a real population adjusted for mortality levels and is independent of age structure. ${ }^{19}$

30. Most published modeling studies are at the national or regional level. In their review, Worrall and Chaussalet referred to national or regional models as "long-term policy models" and models used at the local level as "short-term operational models." 20 They noted that one challenge in developing shortterm operational models is that data at the local level often lack sufficient quality, detail, and volume to generate reliable projections of future care needs.

\section{F. Platforms for Decision-Support and Population-Aging Data}

31. There are several international platforms that can guide decisions on which modeling methods to use, which in turn can support the standardization of models and data collection to facilitate international comparability. ${ }^{21}$ There are also international and regional organizations that collate data relevant to modeling. Key platforms for decision-support and population-aging data are in Appendix 2.

\section{SYNTHESIS OF FINDINGS FROM REVIEW OF MODELING STUDIES}

\section{A. Number and Geographic Settings of Modeling Studies for Long-Term Care Needs}

32. For the review of modeling studies summarized in this paper, relevant publications between 2005 to February 2019 were located. Thirty-one publications were identified worldwide. This included 17 papers reviewed by Worrall and Chaussalet (2014) covering 2005-2011,22 and a further 14 papers and reports published 2012-February 2019. A further 3 studies prior to 2012 that were not included in Worrall and Chaussalet's review were also identified.

33. Of the 17 studies reviewed by Worrall and Chaussalet, only 1 was from an LMIC (the People's Republic of China [PRC]). Of the remaining papers identified, 14 reported on LTC projections for highincome countries. One included all Organisation of Economic Co-operation and Development (OECD) countries as well as the "BRIIC" countries-Brazil, the PRC, India, Indonesia, the Russian Federation, and South Africa. ${ }^{23}$ Two papers reported LTC projections for the PRC. Since 2008, researchers in Thailand have calculated four different future estimates of the need for LTC, each using a different approach. ${ }^{24}$ Only two of these were accessible and reviewed.

19 Sullivan's Method, Glossary, Eurostat, Statistics Explained, Eurostat

20 P. Worrall, and T. Chaussalet. 2014. A Structured Review of Long-Term Care Demand Modelling. Health Care Management Science. 18 (2).

${ }^{21}$ R. Astolfi, L. Lorenzoni, and J. Oderkirk. 2012. A Comparative Analysis of Health Forecasting Methods. OECD Health Working Papers. No. 59. Paris: OECD.

22 P. Worrall, and T. Chaussalet. 2014. A Structured Review of Long-Term Care Demand Modelling. Health Care Management Science. 18 (2).

23 The 34 OECD member countries are Australia, Austria, Belgium, Canada, Chile, Czech Republic, Denmark, Estonia, Finland, France, Germany, Greece, Hungary, Iceland, Ireland, Israel, Italy, Japan, the Republic of Korea, Latvia, Lithuania, Luxembourg, Mexico, the Netherlands, New Zealand, Norway, Poland, Portugal, Slovak Republic, Slovenia, Spain, Sweden, Switzerland, Turkey, the United Kingdom, and the United States.

24 S. Sasat, and T. Sakunphanit. 2018. Thailand Country Diagnostic Study Report: Strengthening Developing Member Countries' Capacity in Elderly Care. Unpublished. 


\section{B. Characteristics of the Modeling Studies for Long-Term Care Needs}

34. Across the studies, a wide range of aims, age groups, forecasting time horizons, types of services, and costs included in modeling LTC expenditure and models were used. This diversity contributes to considerable variation in current and projected estimates of rates and numbers of older people with disabilities and projections for LTC costs. There are also clear differences between the situation in high-income countries that have been aging for longer and more slowly and have well-established LTC systems. Despite this diversity, there are useful lessons for the development of predictive models to be drawn from these studies.

35. Study aims. The aims of the modeling studies include projecting future numbers of older people and their care needs, projecting care need and demand, projecting care costs (including formal services in delivered in different settings), and testing policy settings or options. ${ }^{25}$ Others addressed the projected hours of care required by family members in the PRC, for example. ${ }^{26}$ Another focused on projected trends in the prevalence and mortality of dementia among older people in Hong Kong, China. ${ }^{27}$ One from Australia, describing the separate modeling of "need for" and "use of" aged care services, allowed investigation of the unmet need. ${ }^{28}$ Finally, one described the development of a new combined model exploring how changes in arrangements for future care of people living with dementia, including support for informal caregivers, could result in better outcomes and more efficient use of resources. ${ }^{29}$

36. Age groups. The papers used a range of age groups in their models. Eleven studies used the age groups 65-74 years, 75-84 years, and 85 years and older, while five studies used 60-69 years, $70-79$ years, and 80 years and older. One used the age groups $65-69$ years, $70-74$ years, $75-79$ years, and 80 years and older. The age groups used are important as they make a considerable difference in population estimates and can make comparisons difficult. It is also important to disaggregate the "oldest-old" age group (usually defined as 75 years and older or 80 years and older), as it is at more risk of needing care and is growing the most rapidly. In countries and areas that are further advanced in population aging, the oldest-old age group should be further disaggregated to $80-89$ years and 90 years and older as care need continues to rise.

37. Forecasting time horizons. Worrall and Chaussalet's review found that 14 of 17 studies had a time horizon greater than 20 years, with one forecasting 10-20 years ahead, one 5-10 years, and one with a horizon of less than 5 years. Most of the studies since 2012 also had a long time horizon, with 12 papers forecasting more than 2 decades ahead, and 510-20 years ahead.

38. Types of services and costs. Data related to services and costs included in modeling LTC expenditure comprised

(i) costs of family care, although gaps (e.g., measuring opportunity cost or the costs of increased need for health care for caregivers, especially older caregivers) were noted; categories of dependency;

25 P. Worrall, and T. Chaussalet. 2015. A Structured Review of Long-Term Care Demand Modeling. Health Care Management Science. 18. pp. 173-194.

${ }^{26}$ B. Hu. 2019. Projecting Future Demand for Informal Care among Older People in China: The Road towards a Sustainable Long-Term Care System. Health Economics, Policy and Law. 14 (1). pp. 61-81.

27 R. Yu, et al. 2012. Trends in Prevalence and Mortality of Dementia in Elderly Hong Kong Population: Projections, Disease Burden, and Implications for Long-Term Care. International Journal of Alzheimer's Disease.

${ }_{28}$ M. Lawton. 1971. The Functional Assessment of Elderly People. Journal of the American Geriatrics Society. 19 (6). pp. $456-481$

${ }^{29}$ A. Comas-Herrera, et al. 2017. MODEM: A Comprehensive Approach to Modeling Outcome and Costs Impacts of Interventions for Dementia. Protocol paper. BMC Health Services Research. 17 (25). 
(iii) a range of home, community, and institutional services, although when unit costs were developed for models that aimed to forecast expenditure on LTC services, some costs may have been missed, and there was sometimes a lack of clarity on items included;

(iv) health care costs; and

(v) public and private expenditure.

39. Most of the studies assumed that the current mix of LTC services available will continue. However, possible future changes in cost per service unit caused by inflation; real increases in staff salaries; or fluctuations in the prices of assistive devices, supplies, and medication were not always considered.

40. Data sources. In general, the modeling efforts suffered from a lack of good-quality data. Most researchers used secondary sources of data, including national census data, national health surveys when available, and population projections from World Population Prospects. These United Nations population projections, however, report data disaggregated only for 60 and over, 65 and over, and 70 and over age groups, and not by gender. Some studies were able to use data from nationally representative health surveys of older people, however. ${ }^{30}$

41. Where data were lacking, some studies identified data from a similar country or setting to use. For example, Srithamrongsawat et al. used a longitudinal dataset from Australia to calculate the probabilities of older people transitioning between different states of dependency, as these data were not available for Thailand. ${ }^{31}$ There are hazards, however, in extrapolating results from studies in other countries or settings. There can be differences in cohort effects, current risk factors, and policies on LTC, as well as cultural differences in preferences for and use of LTC services. ${ }^{32}$ This has implications, for example on family members caring for dependent older people at home. ${ }^{33}$ Even within countries and areas, relevant variables may be different in different settings, such as between urban and rural locations, or between different socioeconomic or ethnic groups. ${ }^{34}$

42. It is also important to recognize that national data sources may be inconsistent. Even in New Zealand, a small high-income country, estimates of the proportion of older people living in institutional care varied greatly. ${ }^{35}$ Inconsistencies in national data can then be reproduced in estimates reported by international or regional organizations.

30 M. Lagergren, N. Kurube, and Y. Saito. 2018. Future Costs of Long-Term Care in Japan and Sweden. International Journal of Health Services. 48 (1). pp. 128-147; and J. Thompson, et al. 2014. Projecting the Number of Older Singaporeans with Activity of Daily Living Limitations Requiring Human Assistance through 2030. Annals of the Academy of Medicine, Singapore. 43 (1). pp. 51-56.

31 S. Srithamrongsawat, K. Bundhamcharoen, S. Sasat, P. Odton, and S. Ratkjaroenkhajorn. 2008. Projection of Demand and Expenditure for Institutional Long Term Care in Thailand. Bangkok: Health Insurance Systems Research Office. https://www. academia.edu/1351987/Projection_of_demand_and_expenditure_for_institutional_long_term_care_in_Thailand.

32 A. Comas-Herrera, et al. 2017. MODEM: A Comprehensive Approach to Modeling Outcome and Costs Impacts of Interventions for Dementia. Protocol paper. BMC Health Services Research. 17 (25).

33 V. Lou, and Q. Ci. 2014. Ageing under the One-Child Policy: Long-Term Care Needs and Policy Choices in Urban China. International Journal of Public Policy. 10 (4/5). pp. 231-242.

34 P. Khongboon, and S. Pongpanich. 2018. Estimating Long-Term Care Costs among Thai Elderly: A Phichit Province Case Study. Journal of Aging Research. 2. pp. 1-11.

35 J. Broad, et al. 2013. Reports of the Proportion of Older People Living in Long-Term Care: A Cautionary Tale from New Zealand. Australia and New Zealand Journal of Public Health. 37 (3). pp. 264-271. 
43. Modeling methods. Most of the studies used microsimulation or macrosimulation models. The choice of model was largely determined by data availability. Methods included

(i) those adapted to model LTC demand, including trend extrapolation, Markov chains, and grey system theory; ${ }^{36}$

(ii) the integration of the Care Policy and Evaluation Centre macrosimulation approach and the Markov approach into one Bayesian modeling framework; ${ }^{37}$

(iii) ProFamy Extended Cohort-Component Method, with introduction of multistate projections of ADL status transition dynamics for older adult projection; ${ }^{38}$

(iv) a simulation model for policy exploration; and ${ }^{39}$

(v) an actuarial projection based on the Rapid Assessment Protocol developed by the International Labor Organization, which utilizes a simple methodology that builds on single age population projections, single age estimates of labor force participation rates, together with a relatively crude economic scenario using assumptions on gross domestic product growth, productivity, inflation and wages, interest, and poverty rates. ${ }^{40}$

44. Some studies considered that older people's need for assistance and care can change. ${ }^{41}$ Others simply used estimates of the proportion of older people in different age groups with ADL limitations. ${ }^{42}$

\section{Consistency and Comparability of Findings}

45. The importance of presenting findings with clear descriptions of the methods, assumptions, and data sources used is exemplified by two studies from the PRC_Zeng et al. (2015) and Hu (2018) which both aimed to project the numbers of older people with disability and the demand for informal care and to quantify the LTC resources to meet needs. ${ }^{43}$

46. Both studies found that there will be a significant increase in the number of older people who will need care in future years. However, their projected numbers are very different. Zeng et al. reported that in 2030, there will be 19.0-24.9 million older people with disability, while Hu reported that there will be 120.2 million older people with disability. The researchers used a different definition for disability. Applying the same definition used by Zeng et al. to the data used in the Hu model, the figure for older people in need of assistance with ADLs is 38.9 million. Moreover, the definition of older people was also

36 S. Sasat, and T. Sakunphanit. 2018. Thailand Country Diagnostic Study Report: Strengthening Developing Member Countries' Capacity in Elderly Care. Unpublished.

37 P. Worrall, and T. Chaussalet. 2014. A Structured Review of Long-Term Care Demand Modelling. Health Care Management Science. 18 (2).

38 M. Lagergren, N. Kurube, and Y. Saito. 2018. Future Costs of Long-Term Care in Japan and Sweden. International Journal of Health Services. 48 (1). pp. 128-147.

39 J. Ansah, et al. 2014. Implications of Long-Term Care Capacity Response Policies for an Aging Population: A Simulation Analysis. Health Policy. 116 (1). pp. 105-113.

40 O. Prasitsiriphon, et al. 2014. Costing Model for Long-Term Care System in Thailand. Nonthaburi: Health System Research Institute.

41 Y. Zeng, H. Chen, Z. Wang, and K. Land. 2015. Implications of Changes in Households and Living Arrangements for Future Home-Based Care Needs and Costs for Disabled Elders in China. Journal of Aging and Health. 27 (3). pp. 519-550; and B. Hu. 2019. Projecting Future Demand for Informal Care among Older People in China: The Road towards a Sustainable Long-Term Care System. Health Economics, Policy and Law. 14 (1). pp. 61-81.

42 M. Lagergren, N. Kurube, and Y. Saito. 2018. Future Costs of Long-Term Care in Japan and Sweden. International Journal of Health Services. 48 (1). pp. 128-147.

${ }^{43}$ Y. Zeng, H. Chen, Z. Wang, and K. Land. 2015. Implications of Changes in Households and Living Arrangements for Future Home-Based Care Needs and Costs for Disabled Elders in China. Journal of Aging and Health. 27 (3). pp. 519-550; and B. Hu. 2019. Projecting Future Demand for Informal Care among Older People in China: The Road towards a Sustainable Long-Term Care System. Health Economics, Policy and Law. 14 (1). pp. 61-81. 
different. Zeng et al. included those aged 65 years and older, while Hu included those aged 60 years and older.

47. Other likely contributions to the difference in projected numbers are that population data came from different revisions of United Nations population estimates, and data for the prevalence of difficulty with ADLs came from different nationally representative surveys. Zeng et al. used data from the Chinese Longitudinal Healthy Longevity Survey, which has been conducted every 3 years in randomly selected counties and cities of 23 provinces since 1998, covering 85\% of the total population. Data for the Hu model came from the China Health and Retirement Longitudinal Survey, which collects health and aging-related information on people aged 45 and over in households. Baseline interviews were conducted in 2011, with a second wave in 2013. Although both surveys ask about ability to do the same six ADLs, the possible responses are worded differently.

Table: Differences between the People's Republic of China Modeling Studies

\begin{tabular}{|c|c|c|}
\hline & Zeng et al. (2015) & $\mathrm{Hu}(2018)$ \\
\hline $\begin{array}{l}\text { Reported projections for } \\
\text { number of older people } \\
\text { with disabilities }\end{array}$ & $\begin{array}{l}\text { 2010: } 8.4 \text { million } \\
\text { 2020: } 12.7-14.6 \text { million } \\
\text { 2030: } 19.0-24.9 \text { million } \\
\text { 2050: } 37.3-61.8 \text { million }\end{array}$ & $\begin{array}{l}\text { 2015: } 67.7 \text { million } \\
\text { 2020: } 80.6 \text { million } \\
\text { 2030: } 120.2 \text { million }\end{array}$ \\
\hline $\begin{array}{l}\text { Definition of older } \\
\text { person }\end{array}$ & 65 years or older & 60 years or older \\
\hline $\begin{array}{l}\text { Source of population } \\
\text { data }\end{array}$ & $\begin{array}{l}\text { United Nations. 2011. World Population } \\
\text { Prospects: The } 2005 \text { Revision Volume II-Sex } \\
\text { and Age. New York. }\end{array}$ & $\begin{array}{l}\text { United Nations. 2016. World Population } \\
\text { Prospects: The } 2015 \text { Revision. New York. }\end{array}$ \\
\hline \multirow[t]{2}{*}{ Source of disability data } & $\begin{array}{l}\text { China Center for Economic Research, Peking } \\
\text { University. 2002-2005. 2005-2008. China } \\
\text { Health and Retirement Longitudinal Surveys. } \\
\text { Beijing. } \\
\text { Survey question asked about six ADLs: eating, } \\
\text { dressing, bathing, toileting, continence, and } \\
\text { indoor transferring. }\end{array}$ & $\begin{array}{l}\text { China Center for Economic Research, Peking } \\
\text { University. 2011-2013. China Health and } \\
\text { Retirement Longitudinal Surveys. Beijing. } \\
\text { Survey question asked about six ADLs: eating, } \\
\text { dressing, bathing, using the toilet, controlling } \\
\text { urination and defecation, and getting in and } \\
\text { out of bed. }\end{array}$ \\
\hline & $\begin{array}{l}\text { Each ADL item has different specific } \\
\text { responses: I can do it without assistance, I can } \\
\text { do it with some assistance, and I cannot do it } \\
\text { without assistance. }\end{array}$ & $\begin{array}{l}\text { Four possible responses: I do not have } \\
\text { difficulty, I have difficulty but can do it, I need } \\
\text { help, and I cannot do it. }\end{array}$ \\
\hline \multirow[t]{4}{*}{ Definition of disability } & \multirow{4}{*}{$\begin{array}{l}\text { If older person needs help in any one of the } \\
\text { six ADL items } \\
\text { Note: Unclear whether this refers to those } \\
\text { who answered } 2 \text { or } 3 \text {, or only } 3 \text {. }\end{array}$} & Independence (no ADL or IADL disability) \\
\hline & & Mild disability (IADL disability only) \\
\hline & & Moderate disability (one ADL disability) \\
\hline & & $\begin{array}{l}\text { Severe disability (two or more ADL } \\
\text { disabilities) }\end{array}$ \\
\hline Modeling method & $\begin{array}{l}\text { ProFamy Extended Cohort-Component } \\
\text { Method with introduction of multistate } \\
\text { projections of } A D L \text { status transition dynamics } \\
\text { for older adults projection. }\end{array}$ & $\begin{array}{l}\text { Macrosimulation approach (PSSRU model) } \\
\text { and the Markov approach integrated into one } \\
\text { Bayesian modeling framework. Monte Carlo } \\
\text { Simulation technique was used to capture } \\
\text { parameter uncertainty. }\end{array}$ \\
\hline
\end{tabular}

$A D L=$ activity of daily living, $I A D L=$ instrumental activity of daily living.

Source: Y. Zeng, H. Chen, Z. Wang, and K. Land. 2015. Implications of Changes in Households and Living Arrangements for Future Home-Based Care Needs and Costs for Disabled Elders in China. Journal of Aging and Health. 27 (3). pp. 519-550; and B. Hu. 2019. Projecting Future Demand for Informal Care among Older People in China: The Road towards a Sustainable Long-Term Care System. Health Economics, Policy and Law. 14 (1). pp. 61-81. 
48. Despite these differences, it is interesting that the calculated percentage increase in the number of older people with disability between 2020 and 2030 was similar in both studies: $49.6 \%$ in the Zeng et al. study, and $50.8 \%$ in the Hu study.

49. This example highlights the need to invest in building capacity at the national level to interpret and communicate the findings and implications of LTC projection models to policy makers.

\section{Key Projections from Modeling Studies for Long-Term Care Needs}

50. Current and projected estimates of older people with disability. Different methods, definitions, and categorizations of disability used, as well as real differences in prevalence in various settings, led to considerable variation in the current and projected estimates and numbers of people with disability across the studies. There is also great variation in the pace of increase in the numbers of older people in need of LTC. In all studies that projected disability rates, the oldest age group (i.e., 80 years and older) can be expected to show the greatest increase in numbers in need of care. Women in the oldest age group are also projected to have higher rates of disability and need for care than men. The greatest expense on health and LTC services occurs during the month before death, regardless of age. Modeling future need for care can show variations in the pace of increase, which is valuable for planning.

51. Projections of expenditure and value of unpaid care. The estimates from modeling future LTC expenditure suggest that the expenditure on LTC as a percentage of gross domestic product must grow substantially to meet increasing need. When considering potential costs of LTC, it is helpful to consider estimates of the costs of not investing in LTC services-including the cost to the national economy of low participation of women in the paid workforce, as well as increased precautionary savings and reduced consumption. ${ }^{44}$

52. A report on care work by the International Labour Organization analyzed the amount of time spent caring for older people and associated financial costs around the world, and presented recent data that could be used in modeling, including on the extent, features, and intersectional inequalities of both unpaid and paid care work. It surveyed the contribution of unpaid caregivers within their own households, as well as in their wider communities. Additionally, it examined the socioeconomic risks linked to the impacts that the inability to balance work and family responsibilities has on women's labor force participation and access to quality employment. ${ }^{45}$

53. Studies on family care and outcomes over time are also helpful to inform modeling studies and policy making, as they provide information on the dynamics of need, demand, and supply. ${ }^{46}$ For example, a study in six European countries found that most family caregivers were still caring for the older person 1 year after starting. Not surprisingly, where a distant relative or neighbor provided care, the older person was more likely to be in residential care 1 year later. Older people with higher dependency or dementia were also more likely to be in residential care.

54. Policy analysis and economic benefits of investment. The economic benefits of an efficient and universally available LTC system have not yet received sufficient attention. Some models show the

\footnotetext{
44 Y. Zeng, H. Chen, Z. Wang, and K. Land. 2015. Implications of Changes in Households and Living Arrangements for Future Home-Based Care Needs and Costs for Disabled Elders in China. Journal of Aging and Health. 27 (3). pp. 519-550.

${ }^{45}$ L. Addati, U. Cattaneo, V. Esquivel, and I. Valarino. 2018. Care Work and Care Jobs for the Future of Decent Work. Geneva: International Labour Organization. https://www.ilo.org/global/publications/books/WCMS_633135/lang--en/index.htm.

${ }^{46}$ D. Lüdecke, et al. 2018. For Better or Worse: Factors Predicting Outcomes of Family Care of Older People over a One-Year Period-A Six-Country European Study. PLoS One. 13 (4).
} 
impact of implementing different policies. For example, projections from Hong Kong, China showed that if the policy response to the need to build capacity of the LTC system is slow, then the health care sector will face increased demands, and LTC needs will grow more quickly. ${ }^{47}$ Another study, which modeled the effect of different policy responses to the need for LTC, showed that slower responses to building capacity for LTC shift care demands to the acute health care sector and increase total care needs. ${ }^{48}$

\section{CONCLUSIONS}

55. The review of modeling studies for LTC shows that the numbers of older people in need of LTC services can be expected to grow rapidly in LMICs in Asia and the Pacific region in the near future. This anticipated growth in need for care highlights the urgency of active policy responses.

56. The review also shows that there is much variation in projected trends in LTC needs and expenditure in different countries, areas, and settings due to the different methods and types of data used, as well as differences in the way that estimates and findings are reported. This makes meaningful comparisons between studies of need for care challenging. Most studies, to date, that have projected LTC needs are from high-income countries. The LMICs of Asia and the Pacific region differ in relation to the provision of these LTC services, especially the stage and pace of population aging and the development of formal LTC services.

57. Modeling for LTC is a complex process. There are many factors that influence need and demand for LTC and considerable uncertainty about how these factors may change over time. Added uncertainty is also introduced by the methodological difficulties in collecting accurate data to inform models. Sophisticated statistical techniques have been developed and continue to evolve to address these issues.

58. To most people, a statistical model is mysterious-data are put in, and results come out. The quality of the input data is clearly important for meaningful results, but few are able to understand the statistical formulas and processes. It is therefore important to work with statisticians who are skilled at projection modeling. It is not essential to understand their statistical techniques, but it is important to comprehend the concepts and definitions used in modeling to interpret and to use the findings.

59. Communication and data presentation skills are also important to present the findings and their implications to policy makers and those responsible for resource allocation. Despite inevitable uncertainties, if the assumptions made in a model and the data sources are described clearly, the limitations of the results are explained, and the findings are presented with uncertainty estimates, the conclusions can still be useful.

60. Developing capacity at the national level to undertake intermittent modeling studies enables policy makers to project future need and demand for LTC under different scenarios. Such models can also test the future effects of different policy actions. At the subnational level, simple models with a

\footnotetext{
47 B. Hu. 2019. Projecting Future Demand for Informal Care among Older People in China: The Road towards a Sustainable Long-Term Care System. Health Economics, Policy and Law. 14 (1). pp. 61-81.

$48 \mathrm{~J}$. Broad, et al. 2013. Reports of the Proportion of Older People Living in Long-Term Care: A Cautionary Tale from New Zealand. Australia and New Zealand Journal of Public Health. 37 (3). pp. 264-271.
} 
short time horizon, informed by locally collected data and regularly updated to check trends, can provide valuable information for local planning.

61. Other uses for estimates of current and future need, demand, and expenditure for LTC include

(i) advocacy with international, national, and regional policy and decision makers;

(ii) planning rational allocation of resources;

(iii) planning for recruitment, training, certification, management, support, and retention of the LTC workforce;

(iv) increasing understanding of the sensitivity of LTC expenditure in relation to influencing factors; and

(v) stimulating and evaluating new strategies to design and to manage cost-effective services.

62. Forecasts from modeling can also demonstrate how investment in LTC services, and the development of an LTC workforce, would stimulate the national economy through opportunities for employment, for small local enterprises to provide services, and for women currently caring for older family members to join the workforce. However, even with modeling studies in OECD countries, such as Australia, the United Kingdom, and the United States, resource allocation has not been sufficient to ensure that their LTC systems are adequate to meet increasing needs. ${ }^{49}$

\section{RECOMMENDATIONS}

63. Recommendations are as follows:

(i) National governments should build capacity to model projections of need, demand, and expenditure for LTC services to inform system design and planning. This should form part of the development of a broader LTC information system to ensure the collection and analysis of quality and comparable data at national and local levels.

(ii) An audit of data required for modeling LTC projections, including to inform the development of unit costs, should be supported, and funds should be made available to enable research to fill data gaps.

(iii) Universities or research institutes should be encouraged to commission and to fund modeling studies to project need, demand, and expenditure for LTC services.

(iv) National research institutes and funding bodies should encourage and support longitudinal studies of factors that influence need and demand for LTC services, and universities should be encouraged to add these subjects to their research agendas. Qualitative studies can complement and help inform the design of modeling studies.

(v) Decisions on the statistical approach to use for modeling LTC need, demand, and cost should be informed by a review of advances in modeling techniques and the availability of data.

${ }^{49}$ R. Humphries, et al. 2016. Social Care for Older People: Home Truths. https://www.kingsfund.org.uk/sites/default/files/field/ field_publication_file/Social_care_older_people_Kings_Fund_Sep_2016.pdf; and R. Stone, and N. Bryant. 2012. The Impact of Health Care Reform on the Workforce Caring for Older Adults. Journal of Aging \& Social Policy. 24 (2). pp. $188-205$. 
(vi) A priority should be to prepare current estimates of need for LTC services, where they are not yet available. Such a study has recently been published from Myanmar. ${ }^{50}$

(vii) Reports of modeling studies should consider the definitions of the LTC services included, definition of the population being addressed, definition of care need and how the need is measured, data sources and assumptions used, method and data sources used to develop unit costs and the rate of inflation applied, start and end dates for the projections, and statistical uncertainty associated with the findings.

(viii) Capacity should be built to interpret and to communicate the findings of modeling studies in ways that policy makers and other nonstatisticians can understand.

(ix) Modeling that enables understanding of the potential impact of different policies on older people and their caregivers, LTC services and their providers, the health care system, and the economy should be encouraged.

(x) Modeling projected need, demand, and cost should be part of a broader situation analysis about current services available and the social, economic, and political challenges to establishing or strengthening LTC systems. Qualitative research about knowledge, attitudes, beliefs, and practices with older people, caregivers, health care providers, LTC providers, and policy makers should complement the findings of statistical modeling.

50 B. Teerawichitchainan, and J. Knodel. 2018. Long-Term Care Needs in the Context of Poverty and Population Aging: The Case of Older Persons in Myanmar. Journal of Cross Cultural Gerontology. 33 (2). pp. 143-162. 


\section{APPENDIXES}

\section{THE WASHINGTON GROUP SHORT SET OF QUESTIONS ON DISABILITY}

The next questions ask about difficulties you may have doing certain activities because of a HEALTH PROBLEM.

1. Do you have difficulty seeing, even if wearing glasses?
a. No - no difficulty
b. Yes - some difficulty
c. Yes - a lot of difficulty
d. Cannot do at all

2. Do you have difficulty hearing, even if using a hearing aid?
a. No - no difficulty
b. Yes - some difficulty
c. Yes - a lot of difficulty
d. Cannot do at all

3. Do you have difficulty walking or climbing steps?
a. No - no difficulty
b. Yes - some difficulty
c. Yes - a lot of difficulty
d. Cannot do at all

4. Do you have difficulty remembering or concentrating?
a. No-no difficulty
b. Yes - some difficulty
c. Yes - a lot of difficulty
d. Cannot do at all

5. Do you have difficulty with self-care (such as washing all over or dressing)?
a. No - no difficulty
b. Yes - some difficulty
c. Yes - a lot of difficulty
d. Cannot do at all

6. Using your usual (customary) language, do you have difficulty communicating, for example, understanding or being understood?
a. No-no difficulty
b. Yes - some difficulty
c. Yes - a lot of difficulty
d. Cannot do at all 


\section{KEY PLATFORMS FOR DECISION SUPPORT AND POPULATION AGING DATA}

(i) R. Astolfi, L. Lorenzoni, and J. Oderkirk. 2012. A Comparative Analysis of Health Forecasting Methods. OECD Health Working Papers. No. 59. Paris: OECD.

(ii) The European Commission's Directorate-General for Economic and Financial Affairs has published the assumptions and methodologies that it uses to make economic projections for European Union member states to 2070. See The European Commission. 2018. The 2018 Ageing Report: Economic and Budgetary Projections for the 28 EU Member States (2016-2070). Brussels. https://ec.europa.eu/info/sites/info/files/economy-finance/ip079_en.pdf

(iii) University centers in high-income countries that undertake regular modeling to produce projections to inform government policy with updated data, such as the Care Policy and Evaluation Centre of the London School of Economics; the multi-university research group Personal Social Services Research Unit based at the University of Kent; the Stockholm Gerontology Research Center; and Australia's National Centre for Social and Economic Modelling.

(iv) Titchfield City Group on Ageing and Age-Disaggregated Statistics, an international collaboration to improve measurement of older people formally endorsed by the United Nations Statistical Commission in March 2018

(v) United Nations Economic Commission for Europe (UNECE) Task Force on Ageing-Related Statistics

(vi) Gateway to Global Aging Data

(vii) United Nations Economic and Social Commission for Asia and the Pacific annual Population Data Sheet, with a range of key indicators on population dynamics (https://www.unescap.org/ resources/2018-escap-population-data-sheet).

(viii) World Health Organization's SAGE, which compiles comprehensive longitudinal information on the health and well-being of adult populations and the aging process from nationally representative samples in six countries - the People's Republic of China, Ghana, India, Mexico, the Russian Federation, and South Africa. See World Health Organization. WHO Study on Global Ageing and Adult Health (SAGE). https://www.who.int/healthinfo/sage/en/.

(ix) The Global Burden of Disease program, which has recently reported on more standardized and replicable methods to improve the accuracy of population and fertility estimates. See Global Health Data Exchange. Global Burden of Disease Study 2017. http://ghdx.healthdata.org/record/ ihme-data/gbd-2017-population-and-fertility-1950-2017; Global Health Data Exchange. Global Burden of Disease Study 2017 (GBD 2017) Fertility Estimates 1950-2017. http://ghdx. healthdata.org/record/ihme-data/gbd-2017-fertility-estimates-1950-2017; and GBD 2017 Population and Fertility Collaborators. 2018. Population and Fertility by Age and Sex for 195 Countries and Territories, 1950-2017: A Systematic Analysis for the Global Burden of Disease Study 2017. The Lancet. 392 (10159). pp. 1995-2051. 


\section{Projecting the Need for and Cost of Long-Term Care for Older Persons}

With the numbers of older persons in the Asia and Pacific region increasing rapidly, there is a growing urgency to develop and strengthen long-term care (LTC) support systems and services. This working paper aims to enhance the understanding, particularly of policy makers and those planning modeling studies, of using statistical models to project the need, demand, and cost of LTC services. The paper first outlines modeling and its importance. Second, it describes key concepts related to LTC need, demand, and measurement. Then, it identifies key issues to consider when designing and using models. A review of recent modeling studies is also summarized, drawing out lessons relevant to low- and middle- income countries.

\section{About the Asian Development Bank}

ADB is committed to achieving a prosperous, inclusive, resilient, and sustainable Asia and the Pacific, while sustaining its efforts to eradicate extreme poverty. Established in 1966, it is owned by 68 members -49 from the region. Its main instruments for helping its developing member countries are policy dialogue, loans, equity investments, guarantees, grants, and technical assistance. 